\title{
ESPINOSA NO DIREITO CONTEMPORÂNEO OU POR UMA TEORIA DO DIREITO COMO POTENTIA
}

\section{SPINOZA IN CONTEMPORARY LAW OR TOWARD A THEORY OF LAW AS POTENTIA}

\author{
Luiz Carlos Montans Braga \\ Pontifícia Universidade Católica (PUC) - (São Paulo, SP, Brasil)
}

Recebimento: 16 ago. 2016

Aceitação: 10 jul. 2017

\begin{abstract}
Como citar este artigo / How to cite this article (informe a data atual de acesso / inform the current date of access):
BRAGA, Luiz Carlos Montans. Espinosa no direito contemporâneo ou por uma teoria do direito como 'potentia'. Revista da Faculdade de Direito UFPR, Curitiba, PR, Brasil, v. 62, n. 2, p. 9 - 24, maio/ago. 2017. ISSN 2236-7284. Disponível em: <http://revistas.ufpr.br/direito/article/view/48138>. Acesso em: 28 ago. 2017. DOI: http://dx.doi.org/10.5380/rfdufpr.v62i2.48138.
\end{abstract}

\section{RESUMO}

Algumas vertentes do direito crítico apontam limitações ao formalismo e ao legalismo jurídicos. O primeiro movimento do artigo procura mostrar algumas teses de uma das vertentes do direito crítico. Num segundo momento, os conceitos espinosanos serão trazidos à discussão contemporânea sobre a crise do direito para serem somados às explicações propostas pelo direito crítico. Por meio de Espinosa intenta-se, primeiro, recuperar o velho tema do direito natural, com novas roupagens e nova pertinência. Por meio dos conceitos espinosanos de multidão e permanência do direito natural no interior mesmo da cidade, o campo jurídico pode ser compreendido de maneira alargada, infiltrando no debate conceitos apagados ou deslocados pelo formalismo jurídico. Nesse sentido a filosofia espinosana pode ser uma das melhores referências para o direito de resistência em face do formalismo vazio que violenta os membros da cidade no momento mesmo em que se apresenta travestido de expressão de interesses da coletividade. As teses espinosanas podem trazer novos temas e conceitos aos apontados e trabalhados pelo direito crítico, bem como podem dar mais força a concepções emancipatórias do direito.

\section{PALAVRAS-CHAVE}

Legalismo. Direito crítico. Direito como potentia. Espinosa.

\begin{abstract}
Some branches of critical legal studies points the limitations of formalism and legalism. The first part of the article shows some theses about one branch of critical legal studies. Secondly, Spinozian concepts will be brought to the contemporary discussion about the legal field crisis, adding up to the theses of the critical legal studies. Using Spinozian concepts, two aims are to be achieved. The first one is to bring back to the discussions and renew the old theme of natural right. By using Spinozian themes, such as multitude and the permanence, in the city, of natural right, juridical field can be understood as something larger, by bringing to the debate some issues that the formalist conception of law ignores. In this way, Spinozian philosophy can be one of the best references for the legal field of resistance - resistance against the empty formalism that violates the members of the city at the
\end{abstract}


moment that law presents itself as an expression of collective interests. Spinozian concepts can bring new themes and new concepts to that ones pointed by critical legal studies. Besides that, it brings new forces for the emancipatory concepts of legal field.

\section{KEYWORDS}

Legalism. Critical legal studies. Legal field as potentia. Spinoza.

\section{MAPA}

A dogmática jurídica se estrutura em torno dos seguintes conceitos: lei, como vontade do legislador objetivada segundo um ritual previsto no próprio regramento legal; doutrina, como estudo dos especialistas acerca dos institutos e leis positivadas pelo Estado; jurisprudência ou julgados, como decisões tomadas a partir do direito posto para os casos concretos que chegam ao judiciário. Essa é uma entre várias cartografias conceituais possíveis, adotada aqui como hipótese de trabalho ${ }^{1}$.

Algumas limitações constitutivas da dogmática jurídica, que a impossibilitam, como instrumento teórico, de fazer diagnósticos precisos acerca do direito, são apontadas a seguir e, em outro momento do texto, analisadas. Com efeito, seu foco em questões sobre a arquitetura formal do direito - validade, vigência, completude do ordenamento jurídico, hierarquia normativa, etc. - não permite visão interdisciplinar e análises de horizonte amplo.

Uma hipótese que o artigo pretende levantar é a de que essa cartografia conceitual, extremamente influente na teorização e na aplicação do direito, impede que o jurídico seja compreendido por meio de outras teorias, como a espinosana, segundo a qual direito é potência tema que será tratado em momento específico do artigo.

Assim, num primeiro momento, o texto procurará explicitar algumas críticas tradicionais à dogmática jurídica, mostrando que ela possui limitações para compreender o fenômeno jurídico. Serão trabalhadas especialmente análises advindas de algumas linhagens da sociologia jurídica - o que se intitula, aqui, genericamente, direito crítico.

Num segundo momento, o objetivo do artigo, na forma de apontamentos, é o de tratar de algumas teses espinosanas pertinentes ao tema e as acoplar às do direito crítico. O intuito final é o de levantar outra hipótese - a saber, a de que a filosofia do direito espinosana pode alargar ainda mais a compreensão tanto da limitação da dogmática jurídica, seus temas e propostas, como dar maior potência explicativa às teses do direito crítico. Nesse sentido, a teoria espinosana do direito pode ser caminho teórico frutífero a concepções emancipatórias do jurídico.

\footnotetext{
${ }^{1}$ José Eduardo Faria apresenta definição diversa em FARIA, 2002, p. 43, nota 23. Para um debate acerca do tema, em diálogo com a obra de Tércio Sampaio Ferraz Jr., conferir BARBOSA; COSTA; RODRIGUEZ, 2010.
} 


\section{UMA OU DUAS TESES DO DIREITO CRÍTICO ACERCA DO DIREITO CONTEMPORÂNEO}

Passa-se, a seguir, à análise do primeiro momento acima indicado. A questão a ser trabalhada é: o que tem o direito crítico, em algumas de suas vertentes, a dizer acerca da dogmática jurídica?

Segundo um dos representantes do direito crítico² $^{2}$, as razões para as limitações da dogmática jurídica podem ser constatadas pelos argumentos a seguir analisados.

As constituições democráticas contemporâneas, afirma José Eduardo Faria (2005, p. 97-99), trazem em seu rol normativo conteúdos relativos ao valor social do trabalho, à busca de uma sociedade justa e solidária, às políticas públicas voltadas à erradicação da pobreza, etc. Essa proteção, como é sabido, costuma ser inseparável de suas respectivas garantias. No entanto, há dois lados na questão, segundo o autor. Um deles é o de que tais garantias são, conceitualmente, orientações programáticas e limitações normativas impostas à discricionariedade do poder público. O outro lado é que tais orientações somente terão efetividade por meio do mesmo poder público. Ocorre que nem sempre o poder executivo efetiva o conteúdo de tais normas. Em sociedades muito desiguais culturalmente, socialmente, economicamente -, como a brasileira, afirma o autor, muitas declarações normativas relativas aos direitos humanos e sociais, nos termos constitucionais, acabam por ter apenas peso retórico e ideológico. A razão, segundo Faria (2005), é a de que o Judiciário, mais apegado aos formalismos e a uma formação excessivamente civilista, é inepto para aplicar o direito com soluções fundadas em critérios de racionalidade substantiva. Assim, diante de situações não rotineiras, o Judiciário hesita. Desse modo, percebe-se que os direitos humanos e sociais, cantados em verso e prosa “pelos defensores dos paradigmas jurídicos de natureza normativista e formalista”, nem sempre são tornados efetivos por uma justiça "burocraticamente inepta, administrativa e processualmente superada; uma Justiça ineficiente diante dos novos tipos de conflito. [...] É aí, igualmente, que se constata o enorme fosso entre os problemas sócio-econômicos e as leis em vigor.” (FARIA, 2005, p. 97-99).

Em outro estudo do mesmo autor, o diagnóstico de limite e exaustão do paradigma jurídico vigente é exposto nos seguintes termos: “o direito e o pensamento jurídico [...] encontram-se próximos de uma exaustão paradigmática.” (FARIA, 2002, p. 39) E na sequência o autor desdobra a tese com o raciocínio seguinte, ao tratar da influência da globalização sobre o direito. A tese é a de que muitos conceitos e categorias fundamentais à teoria do direito até o momento vão sendo esvaziados e colocados em xeque pelo fenômeno da globalização, por suas diversas facetas e

\footnotetext{
2 Trata-se de José Eduardo Faria, autor cujas teses serão expostas nesta seção. Para uma visão introdutória e panorâmica do tema do direito crítico, consultar WOLKMER, 2002.
} 
consequências. Os códigos interpretativos, modelos analíticos e esquemas cognitivos do direito, veem-se, segundo o autor, cada vez mais carentes de funcionalidade. Perderam, na prática, operacionalidade (FARIA, 2002, p. 39). Para usar uma metáfora, é como se o direito operasse em suas próprias temporalidade e engrenagens, desconectado da dinâmica social na qual deveria estar inserido.

A primeira análise do autor (FARIA, 2005, p. 97-99), acima indicada, mesmo ao tratar mais especificamente dos desdobramentos do formalismo jurídico - de certo modo de compreensão e prática do direito - para o campo da relação entre eficácia e direitos humanos (inclusos os direitos sociais), aponta para uma questão que também é de interesse ao presente artigo - a saber, o das limitações do entendimento do campo jurídico como atrelado à dogmática jurídica. A segunda análise (FARIA, 2002, p. 39) constata que tal exaustão de paradigma, que num primeiro momento traz ao centro das discussões a ineficácia dos direitos humanos e sociais previstos em normas positivadas, se estende, na verdade, a todas as áreas do direito.

E, de fato, o paradigma do formalismo jurídico estreita a compreensão do direito, pois o apreende em dimensão diminuta em relação à sua área de ocupação efetiva. Em outros termos, o direito é mais amplo, conceitualmente, do que as definições e temas propostos pelo formalismo jurídico e pela dogmática jurídica. Por conseguinte, o direito assim conceituado oculta partes importantes da natureza do fenômeno jurídico. Tais partes deslocadas ou não explicitadas pelo formalismo jurídico têm importância para uma compreensão emancipatória do direito.

Na mesma chave de crítica às limitações do formalismo jurídico, bem como da crise de paradigma da dogmática jurídica, posiciona-se Boaventura de Sousa Santos, ao apontar que há uma desorganização do direito estatal ao ser obrigado a coexistir com o direito não oficial. O direito não oficial seria, para Boaventura, o dos múltiplos legisladores de fato. Estes, pela força que têm, transmutam o fato e a força em norma. Nesse sentido, competem com o Estado pelo monopólio da violência e criam um direito paralelo (SANTOS, 2003, p. 13).

Um breve desvio. São muito bem construídos os argumentos de Boaventura de Sousa Santos para constatar a crise do direito como direito positivado pelo Estado e as exclusões, de vastas camadas de pessoas - de uma vida digna, da cidadania, da cultura, etc. -, advindas de fascismos como o do capital financeiro (o termo "fascismo financeiro" é do autor - [SANTOS, 2003, p. 23]). Soam, entretanto, algo ingênuas as constatações do final do referido artigo. Por exemplo, ao afirmar que há o "Estado como movimento social" (SANTOS, 2003, p. 64) quando se constata a prática do orçamento participativo. O exemplo citado pelo autor é o de Porto Alegre. Boaventura afirma ainda 
que tal experiência estaria se espalhando para as esferas regional e nacional. Não foi o que ocorreu ${ }^{3}$. Em suma, discorda-se do autor no que se refere à existência, segundo ele, "hoje em dia, por todo o mundo, [de] um sem número de exemplos concretos de experiências políticas de redistribuição democrática dos recursos resultante da democracia participativa ou de um misto de democracia participativa e representativa.” (SANTOS, 2003, p. 66) Constatam-se, em vez disso, movimentos coletivos de revolta ou reivindicatórios que, espinosanamente, poderiam ser chamados de direito natural coletivo em exercício - o que é diferente de constatar "exemplos concretos de experiências políticas de redistribuição democrática dos recursos resultante da democracia participativa” (SANTOS, 2003, p. 66). Em uma palavra, concorda-se com o diagnóstico, mas não com as projeções que o autor faz a partir daí.

Volta-se ao fio central do artigo. O conceito de direito espinosano parece ser uma chave relevante para que esses terrenos menos explorados venham a fazer parte de uma conceituação mais ampla e emancipatória do direito, a ser considerada para a elaboração da institucionalidade jurídica da cidade.

O que se intenta destacar com as considerações acima é a necessidade de se recorrer às pesquisas de outras áreas do saber para que uma análise acerca da crise do direito possa ser devidamente encaminhada. Isto somente ocorre uma vez que a dogmática jurídica e o formalismo jurídico não são capazes de lançar luz nos problemas jurídicos contemporâneos - afinal, sua compreensão do fenômeno jurídico é demasiado estreita.

Não casualmente, portanto, a vertente crítica do direito acima citada, em contraposição ao formalismo jurídico, toma a dianteira explicativa quando o tema é a crise jurídica contemporânea. Tal vertente faz uso de um leque de áreas do saber que extrapolam as paredes fechadas da dogmática jurídica. E não poderia ser diferente, pois sem este salto de muros nada poderia ser visto. Isto é, um Estado penal ou um Estado que investe em políticas públicas, para análises a partir da dogmática jurídica, seriam semelhantes do ponto de vista jurídico. Isto ocorre na medida em que o objeto de análise principal, para um estudo do direito como expressão da legalidade, é a validade dos sistemas jurídicos de cada um desses Estados, entre alguns outros temas correlatos.

Dentre as várias expressões do direito crítico ${ }^{4}$, recorreu-se e recorre-se, para ensaiar um aprofundamento de suas teses por meio dos conceitos espinosanos, a um de seus representantes - a saber, José Eduardo Faria. A escolha tem duas razões centrais. Primeiro, pelo fato de que há grande originalidade e potência explicativa nas teses de Faria acerca do direito, sobretudo em sua crítica ao

\footnotetext{
${ }^{3} \mathrm{O}$ artigo é de 2003.

${ }^{4}$ Para visão panorâmica do tema, ver, como citado em nota anterior, WOLKMER, 2002.
} 
formalismo, declarando-o paradigma em fase de exaustão, como indicado acima (FARIA, 2002, p. 39). Em segundo lugar, em razão de se poder extrair de Espinosa e de seus conceitos jurídicos e políticos grande capacidade de dar mais vivacidade e poder explicativo ao campo do direito crítico, e principalmente porque Faria não o cita e não faz uso do rol conceitual espinosano. Esta vertente do direito crítico, ora apontada, envereda-se pela sociologia do direito preponderantemente, mas faz uso, igualmente, da economia, da filosofia e da teoria do direito. $\mathrm{O}$ artigo aprofunda, a seguir, alguns temas de destaque dessa versão do direito crítico, os quais podem ser adensados pelos conceitos espinosanos - ponto do qual se tratará após a análise das teses de Faria para o campo dos direitos humanos e sociais.

Em um capítulo intitulado As Novas Formas e Funções do Direito: Nove Tendências, o qual compõe o livro Sociologia Jurídica: Direito e Conjuntura (FARIA, 2010), o autor trata, entre outros temas, da questão dos direitos sociais e dos direitos humanos, bem como do fortalecimento do Estado penal. Tais temas são analisados em duas das chamadas nove tendências do direito contemporâneo.

Sobre a situação dos direitos sociais e dos direitos humanos, o diagnóstico não é de avanço, mas de retrocesso. O autor, aprofundando teses já expostas em outras obras, acima citadas (FARIA, 2002, 2005), analisa o direito desenhando tendências, uma vez constatada a exaustão do paradigma positivista (FARIA, 2002, p. 39). E uma das tendências do direito contemporâneo é o do aumento no ritmo de regressão dos direitos humanos e, dentro desses, dos direitos sociais, todos consagrados pelo direito positivo. Os motivos seriam os seguintes. Por um lado, o enxugamento do Estado-nação e a retração da esfera pública reduzem, consequentemente, a cobertura legal e judicial desses mesmos entes. E, por conseguinte, o alcance jurídico-positivo dos direitos humanos acaba igualmente diminuindo. Isso, de acordo com o autor, implica um rebaixamento qualitativo da cidadania. Por outro lado, os direitos sociais dependem de orçamento suficiente que financie políticas públicas para sua efetivação. Assim, princípios básicos inerentes aos direitos humanos - dignidade, igualdade, solidariedade e inclusão econômica - são enfraquecidos em razão dos fatores acima, ao serem colocados face a face com imperativos da economia globalizada, a qual exige um Estado mínimo ou comprometido com políticas de estabilidade macroeconômica, estímulo à competitividade, corte de custos, etc. (FARIA, 2010, p. 104-105).

O tema já fora objeto de aprofundamento por Faria em outro texto (FARIA, 2009). Neste estudo, afirma que no período dos governos social-democratas do pós-Guerra e das constituições dirigentes que se seguiram aos períodos autoritários, o poder político dos Estados se impunha de maneira inconteste aos capitais financeiros. Porém, na passagem do século 20 ao 21, devido a uma série de razões, entre as quais a desterritorialização dos mercados e o advento dos grandes 
conglomerados, o Estado nacional perdeu parte de sua força como instância de mediação política e regulamentação. A consequência é precisamente que as condições de efetivação dos valores democráticos diminuem em razão da diminuição do poder dos Estados ante essas novas condições. Em suma, quanto maior a internacionalização do capital financeiro, menor o poder dos Estados soberanos sobre este capital, menor a sua força para promover justiça social pelas vias fiscais. Com efeito, os detentores do grande capital financeiro barganham nas cidades, estados e países melhores condições fiscais, e ante os sindicatos e instâncias trabalhistas, menores salários, entre outras vantagens, como contrapartida à sua instalação no local (FARIA, 2009, p. 304-305).

No que se refere à metamorfose do Estado, passando de um Estado que investe em políticas públicas a um Estado penal, o autor constata o primado da Lei e Ordem, no âmbito penal, por meio de uma crescente criminalização de condutas. Tal caminho estatal é impulsionado por campanhas de desqualificação de propostas alternativas. Essa tendência se dá em simultâneo a uma deterioração difusa do tecido social, criminalização em massa, violência urbana e multiplicação de espaços em que a autoridade estatal não tem qualquer eficácia, não se impõe (FARIA, 2010, p. 107).

Conclui o autor que a política de ênfase na eficiência punitivo-repressiva encerra o risco de “criminalizar sumariamente os marginalizados, do ponto de vista socioeconômico, sem qualquer objetivo mais consistente de disciplina, de recuperação e de ressocialização no âmbito especificamente penal.” (FARIA, 2010, p. 110) E conclui, no mesmo sentido, que "enquanto nos demais ramos do direito positivo vive-se uma fase de desregulamentação, deslegalização e desconstitucionalização, no âmbito do direito penal verifica-se justamente o inverso.” (FARIA, 2010, p. 111$)^{5}$

Boaventura de Sousa Santos elabora diagnóstico semelhante ao de José Eduardo Faria quanto à questão das clivagens presentes nas cidades. Assinala a presença de uma espécie de fascismo social, que se expressa sob algumas formas, como a do fascismo do apartheid social, ou seja, a segregação social dos excluídos por meio da divisão das urbes em zonas civilizadas, de um lado, e zonas selvagens, de outro. As zonas civilizadas (zonas do contrato social, dos castelos neofeudais, dos enclaves fortificados, comunidades muradas), segundo o autor, veem-se em constante estado de ameaça pelas zonas selvagens, onde o Estado tem dificuldade de impor suas regras. E, no que se refere ao Estado, seu padrão de ação se dá em dois níveis. De um lado, nas zonas civilizadas, atua de forma democrática, comportando-se como Estado protetor, ainda que de forma ineficaz e não

\footnotetext{
${ }^{5}$ Outro autor que estuda o tema e tem o mesmo diagnóstico é WACQUANT $(1998,1999)$.
} 
totalmente confiável. Nas zonas selvagens, o Estado atua de forma fascista, comportando-se como Estado predador, sem qualquer respeito pelo estado de direito (SANTOS, 2003, p. 21).

A chave da análise de José Eduardo Faria, como a dos demais autores citados, é, eminentemente, sociológica, tomando o direito como objeto (sociologia jurídica), mas com lastro também na economia e na filosofia do direito. Trata-se, em suma, de análises interdisciplinares. O que se pretende a seguir, como apontado, é somar a este diagnóstico alguns argumentos espinosanos sobre a cidade (civitas) e o direito. Isto é, pretende-se mostrar como as concepções espinosanas apontam para a deterioração do corpo da cidade (civitas) no momento em que as leis da cidade, por não extraírem da multitudo seu direito, passam a não possuir potência. Ou seja, as leis deixam de ser, em alguma medida, direito, pois potentia sive jus (TP II 4 p. 12) ${ }^{6}$. Em uma palavra, intenta-se tratar da crise do direito como lei levando em conta o momento em que a lei da cidade não considera a fonte físico-ontológica do seu direito, isto é, a potência do povo livre ou multitudo ${ }^{7}$. E, corolário daí advindo, o direito, que não mais está nas leis da cidade, passa a estar presente em outras instâncias do corpo político, algumas delas ameaçando sua deterioração.

Os conceitos espinosanos, desse modo, mostrar-se-ão capazes de trazer à discussão contemporânea sobre a crise do direito - tema apontado pela vertente do direito crítico acima esboçada - novos elementos. Não apenas por se poder, pela via espinosana, recuperar o velho tema do direito natural, com novas roupagens - não como instância metafísica ou racional, mas como potentia - e enorme pertinência, mas também por outro motivo. Por meio dos conceitos espinosanos de multidão e permanência do direito natural no interior mesmo da civitas, como afirma Espinosa na Carta 50 (Ep. 50 p. 398), o campo jurídico pode ser compreendido de maneira alargada, infiltrando no debate conceitos apagados ou deslocados pelo formalismo jurídico. Nesse sentido, por expandir o conceito de lei - por exemplo, dando-lhe ares de potência (a lei da cidade, para Espinosa, tem fundamento ontológico [MONTANS BRAGA, 2015, p. 47-70]) -, a filosofia espinosana pode ser

\footnotetext{
${ }^{6}$ As obras de Espinosa que serão mencionadas se encontram na edição crítica de Carl Gebhardt (ESPINOSA. Spinoza Opera. Ed. Carl Gebhardt. 4 v. Heidelberg: Carl Winter, 1972 [1ª ed. 1925]). Quando citada a edição de Gebhardt, citarse-á: G, seguido do tomo em romano e da página em arábico. As traduções consultadas são as seguintes: ESPINOSA, 2003; 2008; 2009. Para a E e o TP, usar-se-á a seguinte abreviação: para a Ética E, seguido da parte em romano; D para definições, Def af para definição dos afetos, A para axiomas, Dem para demonstrações, P para proposições, Cor para corolários, Ap para apêndices, L para lemas, Esc para escólios, Post para postulados, Explic para explicações. Um numeral arábico indicará o número de cada um desses itens. Após, a página em arábico. Para o TP, numeral romano indica o capítulo e numeral arábico indica o parágrafo. Após, a página em arábico. Para o TTP, numeral romano indica o capítulo. Após, a página em arábico. Para a Correspondência, Ep, o número da Carta em arábico e a página da edição de Atilano Dominguez em arábico (ESPINOSA, 1988). Assim se procede para facilitar a consulta a qualquer edição das obras de Espinosa, mesmo que seja à custa do não cumprimento estrito das regras de citação da ABNT.

${ }^{7}$ Para a problematização do conceito de multitudo (multidão) livre ou serva, ver, entre outros artigos do mesmo livro, ZOURABICHVILI, 2008, p. 69-80.
} 
uma das melhores referências para o direito de resistência em face do formalismo vazio que violenta os membros da cidade no momento mesmo em que se apresenta travestido de expressão de interesses da coletividade (MONTANS BRAGA, 2015, p. 176-193). Os conceitos espinosanos podem iluminar ainda mais o que o direito crítico é capaz de apontar como pontos de crise do direito, bem como podem dar mais força a concepções emancipatórias do jurídico.

\section{O DIREITO CIVIL DA CIDADE E O PODER DO SÚDITO-CIDADÃO}

Na Ética IV, Espinosa estabelece algumas teses sobre a cidade, as leis e a justiça. Para que os homens vivam em concórdia e possam ajudar-se, é preciso que cedam [cedant] parte de seu direito natural. Mais precisamente, que façam concessões quanto a ele. Ademais, afirma que é preciso que estabeleçam garantias recíprocas de que nada farão que venha a resultar em prejuízo do outro. Espinosa refina o argumento e, para tal, passa a tratar dos afetos. Afirma que há uma lei segundo a qual cada um se abstém de causar prejuízo a outrem por medo - um afeto - de prejuízo maior. E, ponto-chave, um afeto somente pode ser refreado por outro, mais forte e contrário. Logo a seguir, indica que é com base nessa lei que se poderá estabelecer uma sociedade, desde que a cidade avoque para si o direito (a potência) que cada um tem de se vingar e de julgar sobre o bem e o mal. Assim, é preciso que a cidade tenha o poder de prescrever uma norma de vida comum [communem vivendi rationem] e de elaborar leis, as quais devem ser cumpridas por meio de ameaças. Uma tal sociedade, diz Espinosa, chama-se cidade [civitas appellatur]. Os que estão protegidos pelos direitos dessa sociedade chamam-se cidadãos [cives]. Por fim, indica que no estado natural não há ações justas ou injustas. Isso passa a ocorrer apenas no estado civil, no qual se decide, por consenso [communi consensu decernitur], o que é deste ou daquele (E IV P 37 Esc 2 p. 311; G II 237-238).

É por meio da lei segundo a qual o útil é, entre dois bens, o maior, e entre dois males, o menor, que se funda a cidade, portanto. Não é pela razão, mas pelos afetos, que a socialidade da cidade se institui e se mantém. Tudo se passa como em um campo físico-ontológico de forças no qual o direito da cidade deve superar o direito dos cidadãos para que estes, paradoxalmente, tenham direito a algo. De fato, as potências dos homens - seu direito natural -, em estado de natureza, são opiniões (TP II 15 p. 19). É preciso que a cidade, por meio de sua potência coletiva, isto é, do direito civil, das leis que ela dá a si mesma, garanta a potência ou direito natural de cada um de seus constituintes por meio, como diz o texto da Ética, de “ameaças” (E IV P 37 Esc 2 p. 311; G II 237-238).

Espinosa pode afirmar então que a cidade é esta tal sociedade "baseada nas leis e no poder de se conservar”. E concluirá que o justo e o injusto, que não existem no estado de natureza, só são 
conceitos concebíveis na cidade e aferíveis por meio das leis que esta se dá "por consenso [communi consensu decernitur]” e que dizem “o que é deste ou daquele [quid huius quidve illius sit].” (E IV P 37 Esc 2 p. 311; G II 237-238)

As expressões “poder de se conservar [potestate sese conservandi]”, "leis [legibus]”, "justo ou injusto [iustum et iniustum]" e "por consenso [communi consensu]" são fundamentais para compreender que o critério do justo na cidade é a lei, mas não qualquer lei. Tais leis, pelo espírito do texto da Ética, devem ser aquelas definidas pela expressão communi consensu, ou, traduzindo literalmente e realçando a redundância que a língua portuguesa traz: consenso comum.

O texto aponta para a importante constatação de que as leis que não venham do communi consensu não têm potência e podem impedir que a razão pela qual a cidade foi criada - a saber, a preservação do direito natural dos cidadãos - continue a existir. Leis sem potência podem levar a cidade à destruição. Tais leis - de uma tirania, por exemplo (a Turca é citada em TP VI 4 p. 49) -, quando se afastam da potência da multitudo, passam a não ser direito por não possuírem o que define o direito; isto é, por não possuírem potência.

Por isso Espinosa escreve, no Tratado político, que:

deve-se ter em conta que pertence menos ao direito da cidade aquilo que provoca a indignação da maioria. [...] E uma vez que o direito da cidade se define pela potência comum da multidão, é certo que a potência e o direito da cidade diminuem na medida em que ela própria ofereça motivos para que vários conspirem. Há certamente coisas de que a cidade deve ter medo (TP III 9, p. 30).

Não por acaso no imperium (Estado, em tradução precária) monárquico descrito no Tratado político o rei não expressa sua vontade sozinho. Ninguém sozinho tem potência suficiente para governar muitos (TP VI 5 p. 49). Ele apenas explicita a decisão do amplo Conselho (TP VI 15 p. 53; VI 17 p. 54-55). E é importante lembrar que, para Espinosa, o imperium monárquico somente será estável se for determinado pela potência da multitudo. De fato, os fundamentos do estado monárquico puro, descrito nos capítulos VI e VII do Tratado Político, seguem uma única regra, segundo Espinosa: “[...] que a potência do rei seja determinada somente pela potência da [...] multidão e mantida sob a guarda desta.” (TP VII 31 p. 85) E também não é casual que no imperium monárquico os cidadãos tenham armas e formem o exército (TP VI 10 p. 51). Para o equilíbrio de potências esta instituição (cidadãos armados) é fundamental.

Em uma palavra, para Espinosa, a cidade (civitas), isto é, o corpo inteiro do Estado (imperium) (TP III 1 p. 25), tem o poder de dar a si suas leis e de se conservar desde que tais leis, que definem o que é deste e daquele, sejam alimentadas pela potência da multitudo. Sem potência a lei é, tal qual o direito de cada um em estado de natureza, mera opinião (TP VII 2 p. 64). 
A potência da multidão, por meio da imitação dos afetos (MONTANS BRAGA, 2015, p. 134-166), é o conceito espinosano que explica a fundação e a manutenção da cidade. Quando a cidade perde a potência que advém da multidão, por meio de atos do poder soberano que causam o afeto indignação nos súditos (MONTANS BRAGA, 2015, p. 76-82), ela perde sua constituição de civitas. O afeto indignação, quando sentido por grande parte dos membros do corpo político, por meio da imitatio afetiva, é índice de desnaturação daquela forma específica de corpo político. Trata-se do “suicídio” da cidade. As leis, nesse caso, podem não ter o caráter de direito, uma vez que sua potência se esvazia com a perda do fundamento de sua existência. Isto é, a potência da multidão, que outrora estava a sustentar a força da cidade, se canaliza para sua destruição.

Tal rol conceitual - direito como potência, imitação dos afetos, multitudo, lei de natureza do bem maior e do mal menor, direito do poder soberano como potência, etc. - pode ser boa lente para potenciar as análises do direito crítico. É o que se procurará fazer a seguir, ainda que em forma de apontamentos, uma vez que esse tema demandaria aprofundamentos maiores, os quais podem vir a ser objeto de pesquisas futuras.

\section{ESPINOSA E AS ANÁLISES DO DIREITO CRÍTICO}

Analisaram-se na seção acima algumas teses de uma das vertentes do direito crítico, a qual funda seus argumentos em especial no aparato teórico da sociologia jurídica. Por sua visão exterior à dogmática jurídica, tal lente teórica é capaz de captar a exaustão do formalismo jurídico, isto é, sua perda de funcionalidade. Com efeito, o autor analisado afirma que “o direito e o pensamento jurídico, [...] encontram-se próximos de uma exaustão paradigmática” (FARIA, 2002, p. 39) e constata, no mesmo sentido da exaustão paradigmática, “o enorme fosso entre os problemas sócio-econômicos e as leis em vigor.” (FARIA, 2005, p. 99)

No que se refere à esfera dos direitos humanos e sociais, tema que interessa de perto às discussões do direito emancipatório, as constatações não poderiam ser mais claras e menos animadoras. Há, como analisado, regressão quanto à eficácia dos direitos humanos e sociais, principalmente quando se trata de países, como é o caso do Brasil, com sociedades pouco integradas, com fortes discriminações socioeconômicas, culturais e políticas (FARIA, 2005, p. 98). Os dispositivos legais que tratam desses temas, de acordo com as análises do direito crítico indicadas, passam a ter “[...] uma função tópica, retórica e ideológica.” (FARIA, 2005, p. 98)

Ponto que decorre da mesma crise do direito e da exaustão paradigmática é, simultaneamente à regressão quanto aos direitos humanos e sociais, o aumento da presença do Estado penal e, corolário, 
o aumento do número de tipos penais e da força e eficácia do Estado na área penal-punitiva, em contraposição ao Estado de bem-estar social. É o que afirma Faria em outro texto, indicando uma das tendências do direito contemporâneo, havendo, assim, o primado da lei e ordem, com a desqualificação de propostas alternativas, tendência que tem sido alimentada "pela deterioração difusa do tecido social, pela criminalidade de massa, pela violência urbana, pela multiplicação dos espaços onde a autoridade estatal enfrenta dificuldades para se impor de modo efetivo.” (FARIA, 2010, p. 107)

Desse modo, se as análises do direito crítico acerca dos direitos sociais, dos direitos humanos e do direito penal têm consistência, havendo uma regressão quanto aos primeiros (direitos humanos e sociais) e um aumento do poder do segundo (direito penal), Espinosa pode ser uma chave interpretativa do direito contemporâneo que se soma às análises de corte sociológico-jurídico.

Para Espinosa, de fato, a civitas deve ser o lugar de predominância de afetos alegres. Do contrário, a cidade não atende às razões pelas quais foi criada, e se apresenta como solidão (TP V 4 p. 44-45). Ou, se não levar em conta as leis naturais, não será cidade, mas quimera [chimaera G III 293] (TP IV 4 p. 38). Mais precisamente, a fundação e manutenção do campo político são o resultado afetivo da lei natural segundo a qual entre dois males se escolhe o menor e entre dois bens o maior (MONTANS BRAGA, 2015, p. 104-175). Essa lei, firmemente inscrita na natureza de cada homem (TTP XVI p. 237), faz que eles “transfiram”, pela esperança do bem maior, seu direito natural ao poder soberano. Tal “transferência” não é um ato de cálculo racional e não é, a rigor, uma alienação completa. Há, na busca da securitas - afeto alegre decorrente da cessação da dúvida quanto à esperança -, um jogo de potências entre os membros (súditos-cidadãos) da cidade e os responsáveis pela confecção, interpretação e aplicação da lei civil, ou seja, o poder soberano ou aqueles que detêm a incumbência da república (TP II 17 p. 20). Entretanto, como a instância de sustentação do soberano é a multitudo, “onde se articulam, por um lado, a multiplicidade de desejos ou receios, por outro, a potência comum que se afirma em resultado da sua insustentável dispersão” (AURÉLIO, 2000, p. 275), o soberano tem limites ao exercício da sua potência. Caso extrapole tais limites, o afeto indignação (MONTANS BRAGA, 2015, p. 76-82), pelo mecanismo da imitatio afetiva, ao ser capilarizado nos membros da multidão - como que por uma só mente é o mecanismo que dá vida à multitudo -, pode desnaturar aquela específica configuração ou estruturação do corpo político por meio do jogo de potências e de afetos entre multidão e soberano. Por essa razão os membros do poder soberano, ou seja, aqueles que detêm a incumbência da república (TP II 17 p. 20), que fazem, interpretam e aplicam a lei, não têm direito - ou seja, potência - de "fazer com que os homens voem” e "que olhem como honroso o que provoca riso ou náusea” (TP IV 4 p. 39). Pois, como conclui 
Espinosa, “Assassinar e espoliar súditos [...] e coisas semelhantes convertem o medo em indignação e, por consequência, convertem o estado civil [statum civilem - G III 293] em estado de hostilidade [statum hostilitatis - G III 293].” (TP IV 4 p. 39)

O parágrafo acima objetivou recuperar, em breves palavras, a discussão presente na política de Espinosa (MONTANS BRAGA, 2015, p. 104-175). Tal olhar em panorama tem por objetivo trazer, num lance, os principais conceitos espinosanos que podem ser somados às análises do direito crítico. De fato, como já afirmado, Espinosa traz elementos novos à discussão proposta pelo direito crítico, mostrando, pelo mecanismo afetivo, como a lei civil ganha ou perde potência, e como a cidade se torna, nessa medida, lugar da fortaleza do ânimo ou da solidão (TP V 4 p. 44-45), sendo que neste último caso deixa de ser civitas $^{8}$.

Essa é uma lição-chave da filosofia política de Espinosa ao direito crítico. É o ponto conceitual em que as teses espinosanas podem trazer ao direito crítico, ao menos em sua versão esboçada neste artigo, contribuições quanto a dois pontos. Primeiro, quanto ao alargamento do conceito de direito e à pertinência do conceito de direito natural. Com efeito, o conceito de direito da concepção espinosana coloca em pauta a importância da potência de cada homem como intensidade finita da e na substância ${ }^{9}$, conceito que se articula a uma busca de vida digna, por meio da experiência de afetos alegres, para além da mera preservação da vida - como é o caso na concepção hobbesiana. Esta maior exigência, em Espinosa, do conceito de potência dos homens permite sua inserção, de maneira pertinente, no seio mesmo da reflexão jurídica crítica. Como consequência, há um segundo ponto de soma ao direito crítico. Ao se alargar a geografia do direito, reconceitualizando-o, o que é conduta passível de penalização para o formalismo e para o Estado penal, passa a ser movimento coletivo do direito resistindo a todo Estado que dissemina no corpo político afetos tristes, como o medo e o desespero, gerando a solidão. De fato, as condutas dos movimentos coletivos, os quais se contrapõem, como potência conjunta, por imitatio afetiva - por exemplo, da esperança de bens maiores, ou da indignação em face do soberano -, em relação às violências de muitos Estados, passam a ser entendidas como direito coletivo, e não como infração à lei.

Pois se o Estado não é capaz de capilarizar, por meio de suas instituições, um imaginário de futuro-como-securitas nas mentes dos súditos no presente - ou seja, um futuro-seguro-imaginado-

\footnotetext{
${ }^{8}$ Para uma análise aprofundada de algumas ideias centrais que circulavam nos séculos dezessete e dezoito, passando pelos principais filósofos do período - colocando em relevo a história intelectual da modernidade e do iluminismo -, ver ISRAEL, 2006.

${ }^{9}$ Para o conceito de substância, ver CHAUI, 1999. Para os fins deste artigo, basta compreender que substância, para Espinosa, é o mesmo que natureza imanente (ou o mesmo que Deus): é única, nada há fora dela e tudo o que há é expressão da potência da e na substância. Os homens são intensidades finitas (modos finitos) da e na infinita potência da substância.
} 
como-presente e garantido por instituições -, está-se mais próximo do que Espinosa define como sendo a característica do imperium turco. Nesta organização política, a duração da paz - aqui entendida como ausência de guerra - foi longa. Entretanto, como assinala Espinosa, "se a servidão, a barbárie e o isolamento se devem apelidar de paz, então não há nada mais miserável para os homens do que a paz.” (TP VI 4 p. 49)

Usando o arcabouço conceitual da filosofia espinosana, pode-se dizer que o Estado penal, ao tomar, cada vez mais, o lugar do welfare State, apenas distancia as leis do direito. Leis que diminuem a potência do direito natural dos cidadãos, seja com a desregulamentação no âmbito do direito público, seja com o aumento das condutas criminalizadas pelo direito penal, apenas distanciam o Estado da multitudo. Sem a potência da multitudo, diria Espinosa, a cidade, corpo inteiro do imperium (TP III 1 p. 25), pode ser fraturada pela indignação das potências dos marginalizados de toda espécie.

Outro desdobramento, com implicações à teoria do direito, consiste em tomar Espinosa como autor a ser considerado pelas concepções do jurídico que se pretendam emancipatórias - como se fez acima, em forma de apontamentos. Além de se afastar das teses do direito como dever-ser, definindo-o como sinônimo de potentia, Espinosa introduz outra importante inovação. Trata-se do fato de que compreende o direito no interior do político e esta instância, por sua vez, não existe sem o campo afetivo. O afeto indignação, por exemplo, como já apontado, se causado pelo poder soberano nos cidadãos, pode, por meio do mecanismo de imitação afetiva, disseminar-se e levar à derrocada da cidade que não mais representa e acolhe a multidão. Pois, como afirma Espinosa, o fundamento da cidade é a multidão. O que nos textos constitucionais e nas teorias formalistas do direito pode passar como mera fórmula vazia - ou seja, o povo como origem do poder -, em Espinosa ganha formulação precisa e rigorosa. A multidão - formada pelos desejos dos homens, em conflito ou em comum, e pelos demais afetos experienciados por eles - é que dá o tom do poder e do direito. O poder soberano que se afasta dos cidadãos, incutindo na cidade afetos tristes e especialmente a indignação, tem como futuro o abismo. Ao trazer tais temas e conceitos à teoria do direito, Espinosa é capaz de dar mais potência e finura teórica ao direito crítico. 


\section{REFERÊNCIAS}

AURÉLIO, Diogo Pires. Imaginação e Poder: Estudo sobre a Filosofia Política de Espinosa. Lisboa: Edições Colibri, 2000.

BARBOSA, S. R.; COSTA, C. E. B. S.; RODRIGUEZ, J. R. Formalismo, dogmática jurídica e estado de direito: um debate sobre o direito contemporâneo a partir da obra de Tercio Sampaio Ferraz Jr. Cadernos Direito GV, v. 7, n. 3, maio 2010. Disponível em: <https://goo.gl/up6AmB>. Acesso em: 7 jul. 2017.

CHAUI, Marilena. A Nervura do Real. v. 1. São Paulo: Companhia das Letras, 1999.

ESPINOSA. Correspondencia. Introducción, traducción, notas e índices Atilano Domínguez. Madrid: Aliança editorial, 1988.

ESPINOSA. Ética. Tradução Tomaz Tadeu. Belo Horizonte: Autêntica, 2008.

ESPINOSA. Spinoza Opera. Ed. Carl Gebhardt. 4 v. Heidelberg: Carl Winter, 1972 [1ª ed. 1925].

ESPINOSA. Tratado Político. Tradução Diogo Pires Aurélio. São Paulo: Martins Fontes, 2009.

ESPINOSA. Tratado Teológico-político. Tradução, introdução e notas Diogo Pires Aurélio. São Paulo: Martins Fontes, 2003.

FARIA, José Eduardo. Direitos humanos, direitos sociais e justiça. São Paulo: Malheiros, 2005.

FARIA, José Eduardo. O direito na economia globalizada. São Paulo: Malheiros, 2002.

FARIA, José Eduardo. Poucas certezas e muitas dúvidas: o direito depois da crise financeira. Revista Direito GV, n. 10. São Paulo, jul./dez. 2009, p. 297-324. Disponível em: <https://goo.gl/GnY8JW>. Acesso em: 14 mar. 2015.

FARIA, José Eduardo. Sociologia jurídica: direito e conjuntura. Série GVlaw. São Paulo: Saraiva, 2010.

ISRAEL, Jonathan I. Enlightenment contested: Philosophy, modernity, and the emancipation of man 1670-1752. Oxford: Oxford University Press, 2006.

MONTANS BRAGA, Luiz Carlos. Trama afetiva da política: uma leitura da filosofia de Espinosa. 2015. 240 f. Tese (Doutorado em Filosofia) - PUCSP, São Paulo, 2015. Disponível em: <https://goo.gl/JGmdLQ>. Acesso em: 8 ago. 2016.

SANTOS, Boaventura de Sousa. Poderá o direito ser emancipatório? Revista Crítica de Ciências Sociais, n. 65, p. 3-76, 2003. Disponível em: <https://goo.gl/QUwtZp>. Acesso em: 12 mar. 2015.

WACQUANT, Loïc. L'ascension de l'État pénal en Amérique. Actes de la recherche en sciences sociales. De l'État social à l'État pénal, v. 124, 1998, p. 7-26. Disponível em: <https://goo.gl/TE6vp6>. Acesso em: 12 mar. 2015.

WACQUANT, Loïc. Les prisons de la misère. Paris: Raisons d’Agir, 1999. 
WOLKMER, Antonio Carlos. Introdução ao pensamento jurídico crítico. 4. ed. São Paulo: Saraiva, 2002.

ZOURABICHVILI, François. L’énigme de la 'multitude libre'. In: JAQUET, Chantal; SÉVÉRAC, Pascal; SUHAMY, Ariel (Org.). La Multitude Libre: Nouvelles Lectures du Traité politique de Spinoza. Paris: Éditions Amsterdam, 2008, p. 69-80.

Luiz Carlos Montans Braga Pós-doutorando em Filosofia, Doutor em Filosofia (2015) e Bacharel em Direito (2000) pela PUCSP. Mestre em Direito pelo Departamento de Filosofia e Teoria Geral do Direito da Faculdade de Direito da USP (2004). Licenciado em Filosofia pela USP (2003). E-mail: montansbraga@hotmail.com 